\title{
SEMICONDUCTOR SYMPOSIUM
}

The third biennial IUPAP symposium on semiconductors will be held in Trieste, Italy, July 2 - 6. The conference will be on "High Excitation and Short Pulse Phenomena" in semiconductors. Hosted by the International Centre for Theoretical Physics in Trieste, the meeting is sponsored by the Committee for Joint IUPAP-UNESCO

Semiconductor Activities at Trieste, under the auspices of the Italian Ministry for Scientific Research.

The symposium will include the following sessions:

- Femto- and Pico-second
Spectroscopy

\section{- Hot Carrier Transport}

- Non-equilibrium

Plasma

- Plasma Confinement

- Quantum-well lasers

- Many-body effects

- Nonlinear Optics

- Physical Aspects of Laser Annealing

Each session will include keynote review lectures and invited presentations. About one third of the schedule will be reserved for extended discussion. No contributed papers will be given, although informal presentations of late results from the

\section{UCLA CHAPTER REPORT}

\section{Student Chapter Focuses \\ On Distinguished Speakers Program}

The UCLA Chapter of the Materials Research Society has begun a regular program of distinguished speakers for its growing membership and other graduate and undergraduate students. Describing the flagship student affiliate its President, Edward J.A. Pope, says "we're strong and healthy-and growing."

Pope reports that three prominent materials scientists have addressed the UCLA Chapter recently:

Prof. Sumio Sakka of the Department of Industrial Chemistry of Japan's MIE University spoke on the topic, "Glasses and Ceramics by the Sol-gel Process."

Prof. Rustum Roy, head of the Materials Research Laboratory at The Pennsylvania State University (and a founder and Councillor of the MRS) gave, "An Overview of Sol-gel Processing Technology."

Prof. Adrian Wright, Department of
Physics, Reading University, spoke on, "Neutron Diffraction Studies of Amorphous Solids."

"While the Distinguished Speakers Program is a top priority with our Chapter," Pope says, "we have also held regular meetings and co-sponsored several major departmental events, including picnics, mixers and freshman orientation tours. For example, we cosponsored a conference and industrial mixer for visiting businessmen on Oct. 22."

The Materials Research Society actively promotes the establishment of student chapters. Anyone interested in learning first-hand the experiences of the UCLA Chapter is invited to contact Pope through the Department of Materials Science and Engineering, School of Engineering and Applied Science, UCLA, Los Angeles, Calif. 90024. participants will be encouraged.

The deadline for registration and hotel reservation is April 1. For information about the technical program, contact Symposium Chairman Prof. Dr. M. Pilkuhn, Physikalisches Institut, Universitaet Stuttgart, Pfaffenwaldring 57, D-7000 Stuttgart 80, Deutschland. Correspondence regarding registration and finance should reach Prof. A. Frova, Instituto di Fisica G. Marconi, Piazzale Aldo Moro 5, I-00185 Roma, Italia.

\section{Process Industry \\ Sets Meeting on \\ Materials Technology}

A conference entitled "Advances in Materials Technology for Process Industries' Needs" will be held at the Atlanta, Ga., Hilton Oct. 29-31, 1984, to bring together process industry technologists and materials scientists and engineers.

The meeting is sponsored by the Federation of Materials Societies, its 12 member societies, and other organizations involved in materials and processing technologies. It will be managed by the National Association of Corrosion Engineers.

The conference program is being arranged by a steering committee chaired by H.A. Huckins of Halcon SD Technology. Co-chairman is Aziz Asphahani of Cabot Corp. The other members are W.K. Boyd, Battelle; Stanley Margolin, Arthur D. Little Co.; Warren Pollock, Du Pont; David Roth, Allied Corp.; Alfred Rahmel, DECHEMA (West Germany), and Adolph Schaefer, Materials Properties Council.

For information contact Dale Miller, National Association of Corrosion Engineers, P.O. Box 218340, Houston, Texas 77218, phone (713) 492-0535. 